\title{
Analytical, computational and conceptual modeling in service science and systems
}

\author{
Haluk Demirkan • Daniel Dolk
}

Received: 15 October 2010/Revised: 15 June 2011/Accepted: 15 December 2011 /

Published online: 22 March 2012

(C) Springer-Verlag 2012

\begin{abstract}
While the service economy is growing very fast, more organizations are reorienting their processes, tools, and products towards service-oriented applications. This service-oriented paradigm is creating new challenges and opportunities for organizations. In this article, we discuss service science and systems, and provide a conceptual view of the service ecosystem in the context of analytical, computational and conceptual modeling. As service scientists, our ultimate goal should be to develop and provide a science-based approach to the dynamic, scalable, secure, and knowledge-driven design and development of service ecosystems, while in the process fostering the development of academic researchers and industry professionals to work in diverse, interdisciplinary teams for engineering adaptable solutions to distributed computing problems.
\end{abstract}

Keywords Service science $\cdot$ Service systems · Cloud services · Service level agreements $\cdot$ Service-oriented architecture $\cdot$ Software-as-a-service

\section{Introduction}

Service, defined as the application of competencies for the benefit of another, is a kind of performance that is exchanged for value (Demirkan 2008; Spohrer et al. 2007). The value that accrues is derived from the interactions of entities that are known as service systems (Vargo and Lusch 2004). Service systems involve people, processes, technology, organizations and information complemented by models,

H. Demirkan $(\bowtie)$

Arizona State University, Tempe, AZ, USA

e-mail: haluk.demirkan@asu.edu

D. Dolk

Naval Postgraduate School, Monterey, CA, USA

e-mail: drdolk@nps.edu 
metrics, measurements, business rules, and related artifacts (Demirkan et al. 2009; Spohrer et al. 2007). The goal of the service science is to understand service systems and to design, improve, and scale service systems for practical business and societal purposes. Let's start with what we mean by "service."

All services-from knowledge-intensive professions (e.g. business consultant, physician, software engineer, legal council, financial advisor, university professor) to labor-intensive employment in hospitality, personal services, and transportation-have shared characteristics (Bitner and Brown 2006; IBM Research 2004):

- intangible primary products (health, business data, education, etc.) that cannot be easily transported and stored,

- value creation with an external, customer-supplied production factor (brain to be educated, body to be cured, etc.),

- non-standardized, and

- simultaneity of production and consumption (e.g. key airline service is produced while customer is on board) in highly complex service ecosystems.

With information and business services now the fastest growing sectors of the service economy, and with the rise of commoditized business processes, service oriented architectures, service oriented infrastructures, on demand computing, cloud computing and self-service systems, there is a strong, emerging relationship between the study of service systems and the more established study of computational systems (Singh and Huhns 2004). Decision and business processes play a very significant role in these service systems. The application of Information and Communication Technologies (ICT) has the potential to enable the digital transformation of service activities into service models and computational service components, but these technologies can be improved through novel intelligence techniques, models and methodologies to compete in the emerging knowledge-based economy. Growing knowledge of ICT design, execution, storage, transmission and reuse is creating opportunities to configure these technologies into service relationships that create new value (Chesbrough and Spohrer 2006). More specifically, ICT provides the means to improve the efficiency, effectiveness, and innovativeness of service systems through: 1) facilitation of new types of services (e.g. Google, online banking, online travel agency); 2) separation of production and consumption of a service, thus storability, transportability, and access to knowledge-based services (e.g. tax software, online classes); 3) coordination of service systems (e.g. online broker systems, information markets, open innovation platforms); 4) reduction of the costs of service production (e.g. semi- and fully automated call centers); 5) improvement of customer-perceived service quality (e.g. ability to standardize elements of service as well as customize to the individual when appropriate); and 6) integration of customers into service creation and delivery (e.g. online educational services, health information systems, business-to-business solutions).

These service systems often encounter the challenges of a highly competitive, global economy, with high customer expectations, dynamically changing markets and technologies, and a fragmented regulatory environment (Table 1).

Many organizations attempt to overcome these challenges through improved efficiency, quality and speed of their operations, through mergers and networks that 
Table 1 Transition from past to now (Adapted from Demirkan 2008)

\begin{tabular}{ll}
\hline Past & Now \\
\hline Standardization & Customization \\
Transactions & Relationships \\
Focus on goods & Focus on services \\
Cost reduction & Revenue expansion \\
Mass marketing & Individual marketing \\
Limited information sharing & Expanded communication
\end{tabular}

adapt their resource base to changing needs, and through rapid services and product innovation. In other words, they attempt to manipulate what are perceived of as the controllable variables within their service system. However, they often discover that these manipulations lack the necessary scope-mainly because their service ecosystem is much more complex than they anticipated. Changes to the scale of service delivery may impact service quality in unanticipated ways, the introduction of a new service may create demand for different or even more services, and service innovations may unintentionally shift the market from a product to a service quality focus. Unanticipated consequences result in unnecessary costs, lack of responsiveness to customers, and missed opportunities for innovation. For example, manipulating the computer information systems within a service system can result in fragmented service delivery [e.g. see Table 2, adapted from (Rai and Sambamurthy 2006)]. Reduced fragmentation and complexity, improved efficiency, and higher levels of agility in service systems can only be achieved when multiple, complex trade-offs are carefully balanced. The ability to assess these types of tradeoffs are among the key skills of next generation change agents, and an interdisciplinary perspective to nuances associated with such tradeoffs will be key educational and research ingredients.

A services research agenda requires addressing service and technology management strategy that can integrate the heuristic nature of designing, modeling,

Table 2 Challenges of fragmentation: business and ICT processes in selected service industries

\begin{tabular}{ll}
\hline $\begin{array}{l}\text { Health } \\
\text { care }\end{array}$ & $\begin{array}{l}\text { Fragmented processes across payers, providers, and hospitals } \\
\text { Poor quality of patient records }\end{array}$ \\
Accelerating costs and slow responsiveness \\
Financial & $\begin{array}{l}\text { Under-utilized data and silo structures } \\
\text { Banking }\end{array}$ \\
Electronics & $\begin{array}{l}\text { Diminishing customer loyalty with deficient products and services } \\
\text { Challenges in transitioning from mass production to configure-to-order supply chains that } \\
\text { achieve productivity and customer responsiveness }\end{array}$ \\
Retail & $\begin{array}{c}\text { Fragmented systems and under-utilized information across the supply chain from track-and- } \\
\text { trace innovations (e.g. radio frequency identification) }\end{array}$ \\
Telecomm & $\begin{array}{c}\text { Incomplete view of customer because of fragmented systems for billing, customer care, } \\
\text { self-service, and activation of services }\end{array}$ \\
Overall & $\begin{array}{c}\text { Challenges with resource, capacity, risk, human, technology, communication, information, } \\
\text { customer, market etc. management challenges, issues and opportunities }\end{array}$ \\
&
\end{tabular}


representing, and warehousing best practice business processes. This research agenda also requires extending traditional services science semantic approaches, development lifecycles, tools, and standards for the context of business process execution, intra-ecosystem stability/self-organization, inter-enterprise collaboration, and an 'enterprise physics' that remains to be elaborated. Designing and utilizing manageable models of sophisticated service systems requires specific approaches for modeling languages, techniques, tools and methodologies. Service modeling techniques need to address the diverse aspects of service systems while also embracing the wealth of existing modeling approaches from associated disciplines and application domains (Demirkan and Spohrer 2010). Our aim is to facilitate an exchange and evolution of ideas on the above topics across multiple disciplines and to encourage participation of researchers and practitioners from academia and industry by joint discussions on service modeling issues.

This special issue on the Analytical, Computational and Conceptual Modeling in Service Science \& Systems is the culmination of the Decision Technology, Mobile Technologies and Service Science Track of the Hawaii International Conference on System Sciences. The topic of the mini-track led to a wide variety of submissions representing the growth of the modeling in service science and service systems. This special issue focuses on this paradigm, reviews the modeling need for the science of service, investigates its tenets and evaluates relevant modeling approaches to architecture, infrastructure, business processes, workflows and strategy. The five papers accepted for the special issue investigate these issues in different ways.

In the next section, we provide our view of service science, systems (that we define as a service eco-system) and modeling. The papers that comprise this special issue are introduced in section three. In the last section, we discuss some of the major research questions and conclude the special issue.

\section{Service science, service systems and modeling}

Service science, service systems, service-oriented technology and service-oriented computing have evolved as a new paradigm for enterprise systems development, supporting intra-enterprise and inter-enterprise collaboration through access to autonomous, implementation-independent interfaces to software and data services (Singh and Huhns 2004). Figure 1 provides an architectural view of the layers that typically exist in the Service-Oriented Ecosystem, ranging from low-level technology layers to infrastructure layers to application services layers to top-level business processes. These top-level processes represent the strategy and knowledgeintensive business processes that drive the ultimate purpose of the enterprise system, adding value to the organizations involved in the collaborative activity. This architecture contains components that are called service-oriented architecture (SOA), service-oriented infrastructure (SOI), and so forth. OASIS defines serviceorientation as, "A paradigm for organizing and utilizing distributed capabilities that may be under the control of different ownership domains. It provides a uniform means to offer, discover, interact with and use capabilities to produce desired effects consistent with measurable preconditions and expectations" (OASIS 2006). 
Currently, production of majority of the information systems researchers and industry professionals is aligned with the horizontal layers in Fig. 1. Serviceorientation and the prevailing global shift to a services-based economy, however, have together altered the delicate equilibrium between computing infrastructures and the support they provide for business processes. In the emerging services model,

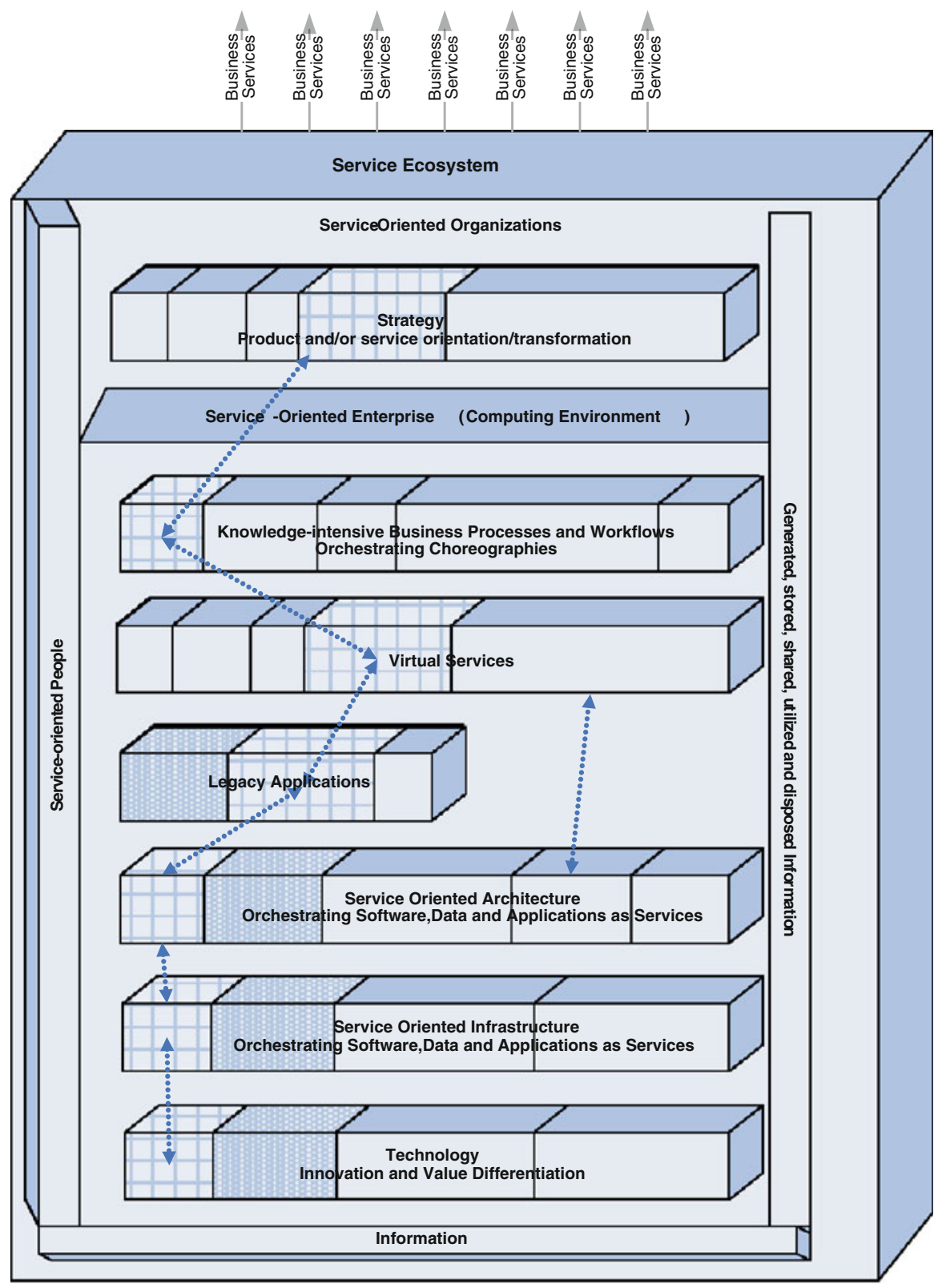

Fig. 1 Enterprise service-oriented ecosystem (Adapted from Demirkan 2008) 
the infrastructure for provisioning services in the ecosystem is characterized by market-driven volatility-business services. This volatility has major implications for dynamic sourcing, and resource and capacity management strategies, requiring a deeper knowledge of how volatility affects interoperability within the horizontal layers and through vertical cross-sections of the layers-a concept that IBM refers to as component business modeling (Demirkan et al. 2009). These dynamic sourcing strategies also imply a need for intelligent and autonomic behavior with respect to participation in collaborative activities (Martin-Flatin 2006), and the support of selfmonitoring, self-healing, and self-management of the service environment in response to the dynamics of the business-to-business (B2B) context as well as the business-to-customer (B2C) concept of self-service (Kephart and Chess 2003). We call this environment a service ecosystem. The term ecosystem was originally used in a computing context by Huberman and Hogg from the Xerox Parc Palo Alto Research Center (Huberman and Hogg 1993), referring to the oscillatory and chaotic behavior that can exist in distributed computational environments. Understanding the complex switching costs for acquiring and interconnecting new services while un-connecting others-and simultaneously provisioning the live services necessary for enterprise continuity-must capture the essence of collaboration with others as an ill-understood ecosystem that is constantly balancing conflicts, such as open versus secure, dynamic versus stable, standardized versus differentiated, innovation versus process (Huberman and Hogg 1993). The concomitant consumption, co-production, and delivery of services require new scientific foundations, research methodologies and trained scholars to investigate emerging equilibrium issues and to realize self-alignment principles.

Service science is at a stage in evolution where it needs to move from conceptual frameworks to the development of analytical and computational models which are integral instruments in the process of scientific inquiry. Models are representations of complex real-world processes and come in many different forms. Analytical models from the fields of operations research and management science (OR/MS) include optimization, dynamic programming, network flows, Markov chains, and econometrics. Computational models draw from the various fields of simulation including discrete event simulation, Monte Carlo simulation, system dynamics, and increasingly, agent-based simulation. Conceptual models such as entity-relationship (E-R), structured modeling (SM), uniform modeling language (UML), and ontology workflow language (OWL) are used in the design of database, operations research/ management science (OR/MS), information and knowledge flow systems respectively.

\section{Papers in this special issue and research agenda}

This special issue focuses on the advancement of service science research and theory by application of analytical, computational and conceptual modeling paradigms to service science management and engineering domains. All five articles herein deal with decision models in one form or another: risk management for service level agreements (SLAs), service provider selection in loosely coupled 
electronic markets, security SLA specification for inter-organizational value networks, a semantically interoperable architecture for linking decision models, predictive analytics models as a service and large-scale agent-based simulation as a service.

The first two papers in this special issue both leverage predictive probabilistic models for resource management allocation in service environments. "Probabilistic Versus Possibilistic Risk Assessment Models For Optimal Service Level Agreements in Grid Computing" by Christer Carlsson and Robert Fuller, is an excellent example of applying analytical modeling to the very complex problem of designing service level agreements in grid computing environments. They apply predictive probabilistic and fuzzy nonparametric regression techniques respectively to develop two risk assessment profiles, the probabilistic and the possibilistic, for assessing the risk of a service level agreement (SLA) for a computing task in a cluster/grid environment. The predictive probabilistic model approximates the probability that a particular computing task can be executed whereas the possibilistic model estimates the degree of possibility of success for this same task. These estimates serve as decision bookends for a resource manager who may choose the more risk-averse probabilistic model, the less risk-averse possibilistic model or some hybrid combination of the two.

Daniel Soper's paper, “One Step Ahead: Using Predictive Inference to Select Service Providers in Loosely-Coupled Electronic Markets," also employs predictive inference models, but in a more general market-based context and with quite a different objective. Using simulation technology, he examines the hypothesis that "customer organizations in a loosely coupled service provider electronic market can achieve superior outcomes by using predictive inference to select service providers when compared to competing customer organizations who behave opportunistically in the selection of such providers". His simulation results suggest that organizations using simple linear regression to select service providers significantly outperform "opportunistic" organizations independent of the latter's optimization criteria. This is a rather striking display of the value of even simple modeling in decision support as echoed by the Kridel and Dolk paper below. Soper's simulation uses a very generic and high level market model that is not tethered to any specific application domain. It would be interesting to see whether his simulation could be adapted to the grid computing environment described by Carlsson and Fuller in order to investigate what impact his predictive inference models may have on risk management and mitigation.

"Taking Value-Networks to the Cloud Services: Security Services, Semantics and Service Level Agreements" by Haluk Demirkan and Michael Goul addresses the very complex problem of how to design the security dimension of cloud based value networks comprised of multiple, loosely federated organizations. This scenario is much more complicated than the single service provider-single customer situation because a value network will have multiple security-based objective functions deriving from its constituent organizations, all of which must be coordinated into a security services bundle in such a way that each organization is satisfied with the outcome. By following design science approach, they propose a cloud service broker model—using semantics and SLA based middleware-to serve 
as a trusted interface between the enterprise, cloud service providers and other organizations collaborating in a value-network. The authors develop a processdriven and semantics-driven conceptual model of dynamic negotiation that first identifies fundamental patterns of collaborative relationships that typically arise in value networks, and then decomposes the security services bundle decision into a set of distinct categories where each category is associated with a specific pattern. Each organization in the value network can then select from the mix of collaborative patterns that are most closely associated with its own strategy, goals and risk profile. The conceptual model consists of six fundamental patterns based upon a contingency table with Centralized vs. Distributed Authority as the rows and Person-Person, System-System and Person-System partner exchanges as the columns. The authors focus upon the most dynamic and complex of these patterns, Person-System exchange with Distributed (Decentralized) Authority, and discuss design requirements for the Online Dynamic Negotiations Approach necessary to implement the security services relevant to this pattern. Specifically, they present a business process-driven Trust Repository design to express trust rankings within a value-network based upon common semantics which can be directly translated into SLA clauses. This flexible approach contributes scope and theory-based perspectives to the security services bundling decision, and enables IT governance for value-network cloud services. The architectural requirements adapt design principles for infrastructure management tailored from approaches to how business cartels historically conducted secure business dealings.

The three articles described above deal with how decision models can be used to implement domain-specific service system applications. The remaining articles in this special issue turn this perspective on its head and explore how models can themselves constitute service systems. Specifically, they all concerned with software as a service (SaaS), a model of software deployment where an application is hosted as a service provided to customers across the Internet with the following characteristics:

- There is network-based access to, and management of, commercially available software;

- Activities are managed from central locations rather than at each customer's site, enabling customers to access applications remotely via the Web;

- Application delivery is typically closer to a one-to-many model (single instance, multitenant architecture) than to a one-to-one model, including architecture, pricing, partnering, and management characteristics;

- There is centralized feature updating, which obviates the need for end-users to download patches and upgrades;

- The software as a service is frequently integrated into a larger network of communicating software - either as part of a mashup or as a plug-into a platform as a service (Demirkan and Goul 2010).

Of particular interest to our special issue is the application of SaaS to decision models in what we call \{decision\} models as a service (MaaS) (Bhargava et al. 1997). MaaS can be thought of as the application of Semantic Web philosophy and technology to the dynamic integration of decision models and their associated data, 
a distributed network-centric view of modeling. The objective of MaaS is to make modeling resources more readily available and reusable to the community of decision-making users.

A classic example of MaaS is presented in "On Semantic Annotation of Decision Models" by Amit Deokar and Omar El-Gayar, which deals with the management of distributed models and data that form the "back stage" of service systems. One of the biggest challenges in interoperability is how to capture application-specific semantics in a sufficiently general way to link with other semantic models. This is particularly acute when thinking about how to reuse and integrate decision models. Given the global nature of service value chains, there is even more demand for managing, sharing, and reusing heterogeneous and distributed resources, both within and across organizational boundaries. Model management systems, which focus on the management of decision models, need to deal with representation, storage, and retrieval of models in such distributed settings. However, existing model representation formats do not adequately support interoperability, accessibility, and contextual information vital for distributed settings. The authors propose a remedy to this shortcoming in the form of a model representation scheme, the Semantically Annotated Structure Modeling Markup Language (SASMML), which incorporates mechanisms for linking semantic models that represent problem domain knowledge concepts. The SASMML model representation technique leverages recent advances in the areas of semantic web and semantic web services which are amenable to a scalable service-oriented architecture for managing models in distributed environments. New service systems will have to be able to use representation techniques such as SASMML in order to integrate existing resources in innovative applications.

The final paper deals with the topic of Software as a Service (SaaS), in the form of advanced modeling and simulation capabilities for clients who do not have the resources or expertise to develop complex modeling applications. "Automated Self-Service Modeling Predictive Analytics as a Service" by Donald Kridel and Daniel Dolk describes a knowledge-base driven automated modeling system for customer targeting applications. The automated modeling approach that they proposed is designed to cost-effectively assist businesses in their targeting activities-independent of the firm's size and targeting needs. This system constructs predictive logistic models dynamically created from clients' data in conjunction with national demographic databases. This effectively provides advanced data mining capabilities for small-to-medium businesses for whom customer targeting is a critical success factor, but who cannot afford the required software and/or analytical model development resources. MaaS application shows one way in which decision technology can be used to leverage the substantive benefits of higher level analytical modeling for clients with lower level modeling sophistication.

Taken together, the five exemplar papers selected in this special issue highlight the increasing need for research on analytical, computational and conceptual modeling in service science and systems, and seek answers to some of the important questions for the service orientation and transformation. 


\section{Conclusions}

Today, the service economy, service orientation and service transformation are growing exponentially. For example, as part of being ICT transformation, the Internet has significantly affected the manner in which most organizations conduct business. Within a single organization, information, data and software services can be highly distributed and deployed among multiple computing platforms. Most organizations must also compete on a global scale, participating in collaborative service systems with their service oriented computational capabilities by conducting electronic business through contact with distributed service providers. Another example can be, more and more product companies are in a process of transforming their product oriented structure to more service oriented.

The articles in this special issue clearly only scratch the surface of the possibilities for research in the analytical, computational and conceptual modeling domains of service science. What we hope they have demonstrated, however, is the fertile ground available for further research and the value of applying increasingly quantitative approaches to analyzing and developing service systems.

This new approach to service-oriented computing will "pose daunting challenges to every user," and will cause an upheaval that has never before been witnessed in the history of information technology (Carr 2005). Advancements for conducting commerce in a service-oriented model will only occur by coupling a hard sciences foundation with a cultural change in the education and research process-one that brings computing, engineering, and business researchers together to study integrated solutions to the difficult challenges of autonomic service computing. This interdisciplinary approach to research and education is essential to the success of the service sector of businesses that drive our economy and quality of life.

This special issue of the Information Systems and e-Business Management attracted state-of-the-art research submissions that investigate new model design and management ideas related to service-science and service-oriented paradigm. A key criterion in the review process was a recognizable contribution to analytical, computational and conceptual modeling in service science \& systems. We also stressed the importance of managerial relevance and the implications of the research. So to bring this scholarly discourse into the IS discipline more fully, we needed to ensure that the selected papers meet the recognized standards for scholarly research and make contributions to management practice.

The guest editors would like to extend our thanks to the anonymous reviewers of these articles. They contributed vital time and effort to help us shape the research for publication, and their ideas, suggestions and critiques are central to the success of the final products. We also would like to thank the Editor-in-Chief, M.J. Shaw for his encouragement and guidance on this special issue project. We further would like to acknowledge the commitment that the authors of the articles in this special issue made to produce high quality work on an expedited schedule for development. Their cooperation and willingness to cheerfully accept and implement the review teams' suggestions were warmly welcomed by us, and made it possible for our work together to be successful. Finally, we hope that the published contents of the special issue will encourage the authors whose papers didn't make it into the special issue to 
continue their research, and to find even greater impetus for making new contributions to knowledge in service science through some of the examples of the research that they find here.

\section{References}

Bhargava HK, Krishnan R, Muller R (1997) Decision support on demand: emerging electronic markets for decision technologies. Decis Support Syst 19:193-214

Bitner MJ, Brown S (2006) The evolution and discovery of services science in business schools. Commun ACM 49:73-78

Carr N (2005) The end of corporate computing. MIT Sloan Manage Rev 46:3

Chesbrough H, Spohrer J (2006) A research manifesto for services science. Commun ACM 49:35-38

Demirkan H (2008) The servitisation of processes, architectures and technologies. Editorial. Int J Serv Sci 1(3/4):197-205

Demirkan H and Goul M (2010) Cloud computing: an organizational perspective. HICSS 43 Symposium on cloud and grid computing services: the next generation of software-as-a-service. January 5, The Grand Hyatt, Kauai Resort \& Spa, Koloa, Kauai, Hawaii

Demirkan H, Spohrer JC (2010) Servitized enterprises for distributed collaborative commerce. Int J Serv Sci, Manag, Eng Technol 1(1):68-81

Demirkan H, Kauffman RJ, Vayghan JA, Fill H-G, Karagiannis D, Maglio PP (2009) Service-oriented technology and management: perspectives on research and practice for the coming decade. Electron Commer Res Appl J 7(4):356-376

Huberman BA, Hogg T (1993) The emergence of computational ecologies. In: Nadel L, Stein D (eds) SFI 1002 lecture notes in complex systems. Addison-Wesley, Boston

IBM Research (2004) Services science: a new academic discipline? The architecture of on De-mand business summit. IBM's T.J. Watson Research Center, Yorktown Heights, NY

Kephart J, Chess D (2003) The vision of autonomic computing. Computer 36(1):41-50

Martin-Flatin J, Sventek J, Geihs K (2006) Self-managed systems and services. Commun ACM 49:3

OASIS (2006) A reference model for service oriented archi-tecture 1.0. Committee specification 1, OASIS reference model technical committee, pp 1-31

Rai A, Sambamurthy V (2006) Editorial notes-the growth of interest in services management: opportunities for information systems scholars. Inf Syst Res 17:327-331

Singh M, Huhns M (2004) Service-oriented computing: semantics, processes, agents. Wiley, Chichester

Spohrer J, Maglio PP, Bailey J, Gruhl D (2007) Steps toward a science of service systems. IEEE Comput 40(1):71-78

Vargo SL, Lusch RF (2004) Evolving to a new dominant logic for marketing. Journal of Marketing 68(1):1-17 